\title{
A presença japonesa no espaço agrário da região Sul da Bahia: a imigração esquecida da década de 1950
}

\section{The japanese presence in the agricultural space of the South region of Bahia: the forgotten immigration of the $1950 \mathrm{~s}$}

\section{La presencia japonesa en el espacio agrario de la región Sur de Bahia: La inmigración olvidada de los años 1950}

Daniel dos Santos Macêdo ${ }^{1}$ https://orcid.org/0000-0003-3556-3789

\footnotetext{
${ }^{1}$ Geografia-bacharelando pela Universidade Estadual de Santa Cruz-Ilhéus-Bahia-Brasil, Departamento de Ciências Agrárias e Ambientais. E-mail: danielcamamu@gmail.com
}

Recebido em: 05/05/2020

Aceito para publicação em: 30/09/2020

\section{Resumo}

Este trabalho se propõe a investigar os nuances da implantação dos núcleos de colonização japonesa criados na Bahia durante a década de 1950, com a justificativa governamental de modernização, desenvolvimento da agricultura local e ocupação territorial. Para tal, o governo brasileiro e o baiano ofereceram conjuntamente aos imigrantes japoneses, dispostos a realizar esta tarefa, uma série de incentivos para que estes viessem a ocupar essas terras, que dentre outras diversas localidades do país e do estado estavam localizadas na região sul da Bahia, mais precisamente nos municípios de Una e Ituberá. Os resultados aqui apresentados são oriundos de fontes secundárias bibliográficas, inclusive entrevistas com os japoneses disponíveis no Centro de Documentação e Memoria Regional da Universidade Estadual de Santa Cruz.

Palavras-chave: Imigração, japonesa, Sul da Bahia.

\begin{abstract}
This work aims to investigate the characteristics of the implantation of Japanese colonization centers created in Bahia during the 1950s, with the governmental justification for modernization, development of local agriculture and territorial occupation. To this end, the Brazilian and Bahian government jointly offered Japanese immigrants, willing to carry out this task, a series of incentives for them to come to occupy these lands, which among other locations in the country and the state were located in the southern region of the country. Bahia, more precisely in the municipalities of Una and Ituberá. The results presented here come from secondary bibliographic sources, including interviews with the Japanese available at the Documentation and Regional Memory Center of the State University of Santa Cruz.
\end{abstract}

Keywords: Immigration. Japanese. Southern Bahia.

\section{Resumen}

Geopauta, Vitória da Conquista, ISSN: 2594-5033, V. 4, n.3, 2020, p.(96-112) http://periodicos2.uesb.br/index.php/geo, 
Este trabajo tiene como objetivo investigar los matices de la implantación de centros de colonización japoneses creados en Bahía durante la década de 1950, con la justificación gubernamental para la modernización, el desarrollo de la agricultura local y la ocupación territorial. Con este fin, el gobierno brasileño y bahiano ofrecieron conjuntamente a los inmigrantes japoneses, dispuestos a llevar a cabo esta tarea, una serie de incentivos para que vengan a ocupar estas tierras, que, entre otros lugares del país y el estado, se ubicaron en la región sur de Bahía, más precisamente en los municipios de Una e Ituberá. Los resultados presentados aquí provienen de fuentes bibliográficas secundarias, incluidas entrevistas con los japoneses disponibles en el Centro de Documentación y Memoria Regional de la Universidad Estatal de Santa Cruz.

Palabras clave: Inmigración. Japonés. Sur de Bahía.

\section{Introdução}

Este trabalho analisa o processo de inserção de imigrantes japoneses nos núcleos coloniais dos municípios de Una e Ituberá, ambos na mesorregião sul da Bahia, estando Ituberá mais ao norte da mesorregião, a 348 quilômetros da capital Salvador e Una, mais ao sul a 503 quilômetros da capital. Apesar da importância histórica, geográfica e política da inserção dos imigrantes japoneses no espaço agrário da região sul da Bahia, as contribuições e nuances da vinda deste contingente imigratório para a região ainda são poucos investigadas. Além disso, cabe também uma análise a respeito das dificuldades enfrentadas por este grupo de indivíduos no processo de migração e adaptação ao contexto regional da época.

Neste sentido, cabe também considerar neste processo a contribuição dos cenários políticos, tanto do Brasil, quanto do Japão no contexto do pós-Segunda Guerra que culminaram com a vinda deste contingente de imigrantes nipônicos para os núcleos coloniais de Una e Ituberá. Estes dois núcleos coloniais tiveram sua origem sobre as mesmas circunstâncias e justificativas do governo em fomentar o desenvolvimento e modernização do campo. Neste contexto, cabe salientar que o processo de imigração para as colônias no Sul da Bahia se deu em um contexto diferente da imigração nipônica iniciada no ano de 1908, com a chegada dos pioneiros da imigração japonesa no porto de Santos a bordo do navio Kasato Maru e que tiveram como principal destino as regiões Sudeste e Sul do país. O período da imigração nipônica que destinou imigrantes para os núcleos coloniais de Una e Ituberá ficou conhecido como a segunda fase da imigração japonesa, fortemente influenciada pelo cenário de destruição enfrentado pelo Japão no contexto imediato do pós II Guerra Mundial. 


\section{O histórico da presença imigrante no sul da Bahia}

A primeira lei que permitiu a estrangeiros o direito à propriedade de terras no Brasil teve sua promulgação em 1808, o governo imperial dava aval a formação de núcleos coloniais nas terras devolutas, não mais sobre o sistema de sesmarias, mas em propriedades de menor porte, a exemplo imigrantes alemães fixados no Sul e Sudeste, no entanto somente a partir de meados do século XIX começaram a chegar em massa outros grupos, os imigrantes que vieram para suprir a demanda da recém findada mão de obra escrava na monocultura do café (OLIVEIRA, 2002).

Os primeiros japoneses a imigrarem com destino aos núcleos coloniais do sul da Bahia partiram do Japão rumo ao Brasil em 1953 a bordo do navio Amerika Maru. O município de Una, diferentemente de Ituberá tem um longo histórico de recebimento de fluxos imigrantes, tendo como destaque o período do final do século XIX, quando houve uma substancial alocação de imigrantes europeus no território do município (MENEZES, 2008; LYRA, 1982). Ao descrever o processo de inserção de imigrantes na região Sul da Bahia, Menezes (2008, p. 36) informa que: "No século XIX, as tentativas de assentar imigrantes alemães em zonas agrícolas na Bahia foram todas, praticamente, feitas no sul do Estado, zona da Mata Atlântica - floresta tropical e clima quente e úmido". Tais afirmações tornam nítidas a concepção de que o espaço agrário regional do sul da Bahia reunia às condições edafoclimáticas favoráveis a prática da agricultura ainda no século anterior a implantação dos núcleos coloniais, haja vista que a agricultura foi uma das principais atividades exercidas pelos imigrantes que se fixaram nas localidades citadas.

Ainda sobre a inserção de imigrantes europeus, o autor Lyra (1982, p.19) acrescenta que "Foram eles localizados, inicialmente, nos núcleos coloniais, denominados Moniz Theodoro, instalado o primeiro próximo à Barra de Comandatuba e o segundo no Rio Una, ambos no atual município de Una”. Ainda que neste primeiro momento nenhuma destas tentativas de inserção de imigrantes na região tenham obtido o sucesso esperado pelo governo da época, tais tentativas demostram o perfil de interesse governamental nos agentes por eles incumbidos do papel de modernização e desenvolvimento da agricultura nacional por mãos imigrantes (SILVA, 2013), bem como o uso de imigrantes para ocupar o território nacional.

O marco do processo de imigração japonesa para a Bahia se dá conjuntamente a criação das três colônias pelo governo brasileiro na Bahia, sob a justificativa de povoar áreas pouco densas demograficamente e improdutivas, sem agropecuária. Com a implementação desta política fundiária e imigratória a intenção do governo brasileiro, em âmbito nacional, era 
de ocupar espaços pouco povoados, expulsar físico-culturalmente os indígenas e promover a valorização fundiária, criando assim, formas econômicas alternativas que dessem condições para transformações na vida social e econômica do país (PETRONE, 1982).

Guiado por essa estratégia foram criadas as três colônias japonesas no Estado: Una e Ituberá no sul do Estado e o Núcleo Colonial Juscelino Kubistchek, localizado no município de Mata de São João, município da região metropolitana de Salvador. A criação do Núcleo Colonial do município de Una se deu por força do Decreto federal $\mathrm{n}^{\circ} 30.390$, de 14 de janeiro de 1952. As terras tinham sido anteriormente transferidas ao governo federal pelo Estado da Bahia (BRASIL, 1952; JESUS, 2015), sendo, portanto, terras devolutas.

Já o núcleo colonial de Ituberá, que inicialmente tinha por objetivo à fixação de trabalhadores rurais assolados pelas secas do interior do Nordeste, numa tentativa de conter o êxodo rural e originalmente não contava com a inserção de nipônicos, foi fundada em 20 de outubro de 1953, por força do Decreto n 34.293 assinado pelo então presidente da República, Getúlio Vargas. O núcleo colonial de Ituberá contava com cinco mil hectares de terras doadas ao governo federal pela Prefeitura Municipal de Ituberá e a S.A. Ituberá Comércio e Indústria (BRASIL, 1953 p. 2 apud JESUS, 2015, p.73).

O núcleo JK, na região metropolitana de Salvador tinha uma área de 4.900 hectares, divididos em cinco fazendas: Luanda, Itapecerica, Quebra Coco, São Pedro e Camaçari, onde em cada uma destas era constituída numa estrutura agrária de pequenas glebas com tamanhos entre 20 e 25 hectares, para cada família de colonos. (BRASIL, 1953 p. 2 apud JESUS, 2015, p.74). Estes centraram suas atividades principalmente na produção hortifrutigranjeiros para o abastecimento do mercado na capital baiana e outras na hinterlândia do município

Já no contexto das colônias de Una e Ituberá (mapa 1) nota-se que apesar das dificuldades iniciais enfrentadas, houve um sucesso relativo nas intenções governamentais, pois as populações nipônicas destes núcleos coloniais são responsáveis pela implantação de culturas como, cravo da Índia, mangostim, pimenta do reino, dentre outras culturas agrícolas de elevado valor agregado e que são de grande importância para a economia agrícola regional. 
Mapa 1- Localização dos municípios de Una e Ituberá na mesorregião Sul da Bahia

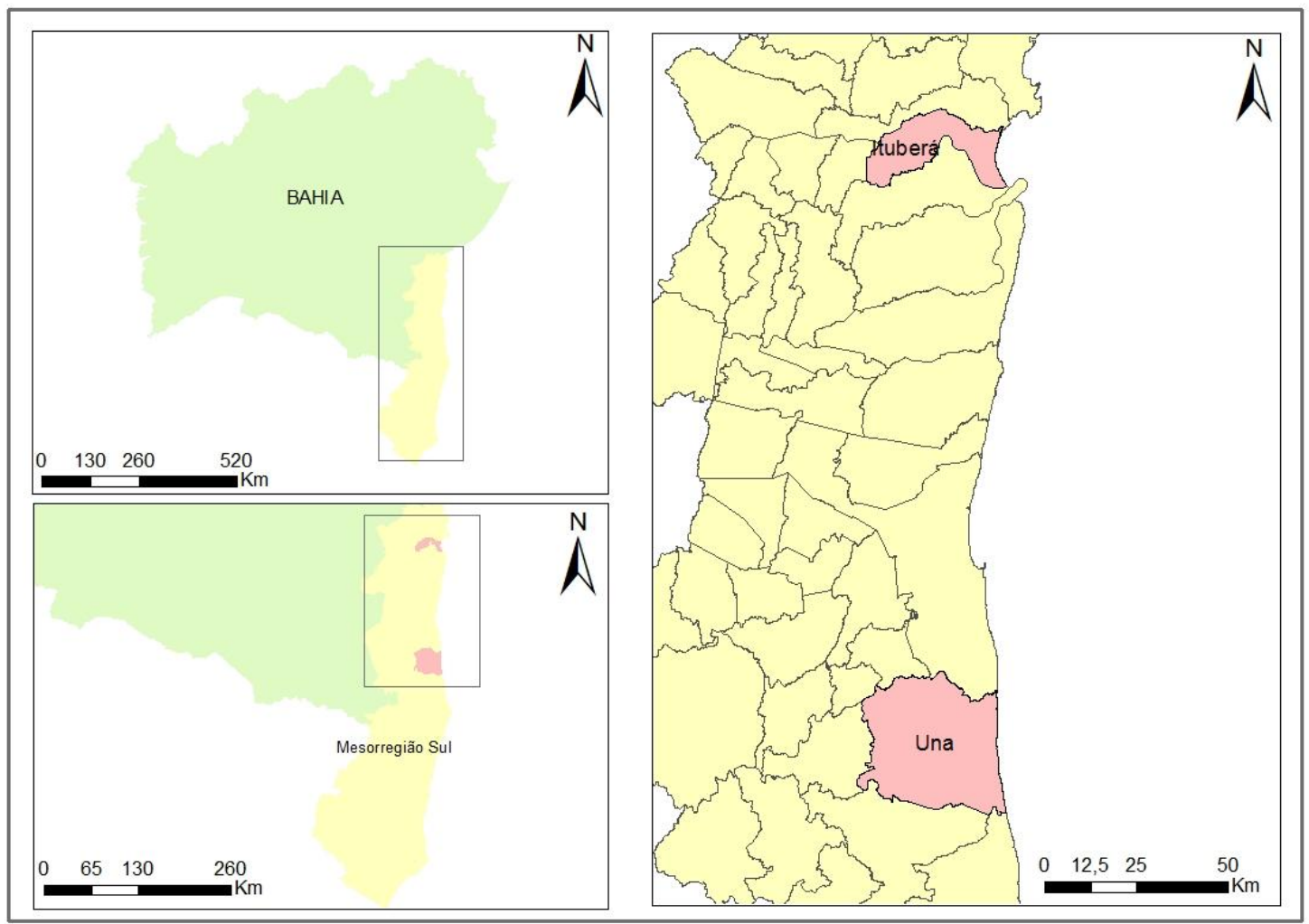

Fonte: SEI (2018). Elaboração do autor(2020)

\section{O fenômeno das migrações e o histórico da imigração japonesa no espaço agrário da região sul da Bahia}

Tratar a temática das migrações é um desafio complexo, é um campo de estudo muito amplo, agrega uma grande quantidade de fatores, como as alterações na dinâmica demográfica com diversos desdobramentos nos mais diversos âmbitos da sociedade.

Para Becker (1997, p. 323), “A migração pode ser definida como mobilidade espacial da população. Sendo um mecanismo de deslocamento populacional, reflete mudanças nas relações entre as pessoas (relações de produção) e entre essas e seu ambiente físico". Dando maior complexidade a esta definição, Maria Cristina Rangel, professora da disciplina Geografia da População, na Universidade Estadual de Santa Cruz, diz que: "migração é o deslocamento territorial de uma multiplicidade de indivíduos, de um determinado lugar-tempo para outro, implicando mudanças nos locais de saída, no percurso, nas paradas, na chegada deles, além de modificações nos próprios migrantes" (ANOTAÇÕES, 2018).

Tal afirmação demostra a complexidade e amplitude de fatores que o fenômeno migratório engendra na sociedade, visto que o indivíduo migrante traz consigo toda uma carga cultural, política, econômica, ambiental, sanitária, exógena aos costumes locais onde o mesmo

Geopauta, Vitória da Conquista, ISSN: 2594-5033, V. 4, n.3, 2020, p.(116-131) http://periodicos2.uesb.br/index.php/geo, 
irá se realocar. Decorre daí as diversas formas de discriminação advindas da ignorância e intolerância, seja dos moradores locais para com os imigrantes, seja o inverso. Tais práticas de intolerância não se limitam apenas aos casos de migração internacional, pode ser amplamente verificado em casos de migração interna e deve ser combatido severamente pelas instâncias legais (BAENINGER et al, 2018), no entanto quando a origem dos indivíduos migrantes têm origem em um local de costumes muito diferentes, a xenofobia e o preconceito, se exacerbam de maneira que no núcleo colonial de Ituberá prevalecia os estranhamentos entre assentados brasileiros e os nipônicos, de tal maneira que as autoridades constantemente buscavam sensibilizar os assentados nacionais apresentando os migrantes japoneses na tentativa de mitigar os conflitos entre os dois grupos de assentados na colônia (JESUS, 2015).

$\mathrm{Na}$ contramão da lógica de intolerância e resistência aos processos migratórios, o sociólogo e demógrafo George Martine, traz a seguinte perspectiva:

A migração é inevitável e tem o potencial de ser bastante positiva para o desenvolvimento e a redução da pobreza. As políticas que partem desse princípio terão mais êxito do que aquelas que tentam se opor, de forma intransigente, tanto à globalização, como à migração de pessoas no espaço (MARTINE, 2005, p. 4).

Deixando claro que nem sempre o processo migratório é negativo, sobretudo em tempos de globalização, no qual pode ser atribuído ao migrante o papel de agente de desenvolvimento no ponto de vista demográfico e de avanço tecno-científico, que de certa forma é um papel que gera controvérsias de ambos os lados, mas que os registros históricos do passado e algumas práticas governamentais do presente, tornam este fenômeno legítimo tendo em vista as políticas governamentais, dentre elas a de subsídios adotadas para atrair os migrantes. Dependendo do contexto histórico e dos interesses dos governos, seja em escala nacional ou internacional, as migrações são incentivadas em nome da garantia da ocupação territorial, do desenvolvimento de novas práticas produtivas, da dinamização das relações sociais e a garantia de soberania sobre o território.

Os primeiros registros da aproximação entre o Brasil e o Japão são datados do século XIX, quando foi assinado o Tratado de Amizade, Comércio e Navegação entre o Brasil e o Japão em 1895, no entanto somente no início do século XX que veio a ocorrer a primeira entrada de imigrantes japoneses no Brasil, nesta época o país já importava mão de obra advinda da Europa desde o fim do regime escravista nas lavouras brasileiras (JESUS, 2015). 
Nesta mesma época o Japão passava por profundas mudanças nas suas estruturas internas nos âmbitos econômicos, sociais e políticos caminhando rumo a industrialização e urbanização como podemos verificar na seguinte afirmação:

Internamente, a economia japonesa que era basicamente agrícola durante a era Tokugawa, passa por um processo de industrialização, que foi importante para o fortalecimento e expansão militar do Japão e promoveu um deslocamento da mão-de-obra para os centros urbanos. A população passa por dificuldades causadas pelo empobrecimento dos proprietários rurais e da população urbana, que sofria com o desemprego estimulado também aumento demográfico e que o desenvolvimento da indústria manufatureira não foi capaz de amenizar (UEHARA, 2008, p. 179).

Estas transformações nas estruturas sociais do país acabaram por produzir dificuldades econômicas atreladas a fenômenos como aumento populacional e da taxa de desemprego. Esse contexto econômico causou tensões sociais que estimularam a imigração no Japão, inclusive com apoio governamental (UEHARA, 2008). Neste contexto de tensão nas estruturas socais do Japão, o Brasil surgiu como alternativa às imigrações japonesas, tendo em vista o Tratado da Amizade, Comércio e Navegação, assinado em 1895. No entanto estas intenções não foram imediatamente concretizadas, pois havia no Brasil um forte movimento de resistência à vinda de asiáticos, endossada pelos argumentos dos movimentos abolicionistas que questionavam a não inserção dos escravizados recém libertos nas cadeias produtivas da época. Entretanto havia uma predileção fenotípica para quem o governo pretendia facilitar o acesso à terra no Brasil e esta não era a dos negros (LEÃO NETO, 1989).

Somente em 1908 foi dado o início a imigração japonesa para o Brasil, neste ano chegou ao porto de Santos o navio Kasato Maru, trazendo 781 migrantes, por intermédio da companhia Kokoku Shokumin Kaisha (UEHARA, 2008, p.184). Esta fase da imigração durou até 1925, quando os japoneses contavam com o apoio do governo do estado de São Paulo. Esta fase não ocorreu de maneira ininterrupta, houve alguns períodos de recesso na chegada de imigrantes, o primeiro entre 1914 e 1916, com a alegação de dificuldades de adaptação dos nipônicos às atividades da lavoura cafeeira e um outro entre 1922 e 1925, que se estendeu ao período de tensão antes da segunda guerra iniciada em 1939, que levaram Brasil e Japão a ocuparem posicionamento antagônicos no confronto (BRASIL, 2004).

Com o término da Segunda Guerra Mundial, a partir de 1952, as relações entre Brasil e Japão se reestabeleceram e as políticas migratórias entre estes passaram a ter um novo 
delineamento. Apesar de institucionalmente a imigração japonesa para o Brasil no período pós-guerra ter sido oficializada somente pelo Decreto $\mathrm{n}^{\circ} 52.920$ de 1963 , do então presidente João Goulart, ainda na década de 1950 houve fluxo de migrantes japoneses para as colônias criadas na Bahia (JESUS, 2015), como podemos conferir na seguinte afirmação:

É certo que os municípios de Una, ao sul do estado, de Ituberá, na região do Baixo Sul, de Mata de São João, na região metropolitana de Salvador, ou ainda Caravelas, Teixeira de Freitas, Santa Cruz Cabrália e Jaguaquara, viram nascer nesse contexto Colônias federais, estaduais ou de caráter espontâneo -nesse caso, formadas pelos dissidentes das chamadas Colônias oficiais. Todas elas abrigariam os imigrantes chegados por via das novas relações estabelecidas entre Japão e Brasil, além de migrantes internos (JESUS, 2015, p. 59).

Foi neste contexto e com o avançar das negociações, que entre os anos de 1952 e 1947 foram criadas pelo governo brasileiro e baiano, as três colônias para ocupação dos imigrantes. Sendo Una, em janeiro de 1952; Ituberá em outubro de 1953 e o núcleo colonial Juscelino Kubitscheck, em 1957, no município de Mata de São João. Os governos federal e estadual tinham como objetivo ao implantar essas colônias a inserção de novas técnicas agrícolas e o povoamento por não índios de terras consideradas improdutivas e abandonadas. Por outro lado, as famílias deveriam oferecer-lhe o rendimento esperado trabalhando muitas vezes em condições sub-humanas, sem o respeito devido, com o agravante dos problemas de ordem social causados pela pouca assimilação da cultura e condições no novo país.

\section{O caráter subsidiado dos núcleos coloniais de Una e Ituberá e a fixação dos imigrantes no espaço agrário regional}

Os moldes nos quais foram implantados os núcleos coloniais na Bahia evidenciam o carácter governamental no surgimento destas colônias amparadas legalmente pelo Decreto-lei $\mathrm{n}^{\mathrm{o}} 7.967$, de 18 de setembro de 1945, que dispunha sobre a imigração e colonização, levando em conta os interesses econômicos e fundiários nacionais decorrentes do fím da segunda guerra mundial (BRASIL,1945).

Para atrair os imigrantes japoneses o governo brasileiro investiu em propagandas que ressaltavam a grandeza e abundância em recursos naturais e este método de convencimento se constituiu em um importante instrumento de divulgação do país, até então pouco conhecido

Geopauta, Vitória da Conquista, ISSN: 2594-5033, V. 4, n.3, 2020, p.(116-131) http://periodicos2.uesb.br/index.php/geo, 
no oriente e despertou o interesse e atração dos japoneses, tendo em vista a realidade vivenciada no Japão com o cenário pós-guerra. Como podemos observar no depoimento oral concedido pelo imigrante Tsuyoshi Isozaki:

Eu acho que, para quem pretendia imigrar, em primeiro lugar, em busca de vida nova, em busca de terras. Porque o Japão é um país pequenininho. Acho que tem $360.000 \mathrm{~km}^{2}$. É bem menor que o estado da Bahia. Então, para aquelas pessoas que somente vivem na lavoura, eles têm o sonho de terra maior, terra fértil, num clima melhor. Então de qualquer maneira, o principal objetivo, era a busca de novas terras. Além disso, quando fala em Brasil, não era Rio de Janeiro nem São Paulo. A primeira coisa que vinha na mente, era Amazônia, uma imensidão de terras férteis com bastante animais e alimentação, a gente sabia do Brasil, era através dos filmes. Inclusive, naquela época no Japão, na década de 40, eu cheguei a assistir filmes de cangaceiro. Agora, eu não sabia nem do que se tratava. Era um faroeste meio estranho. E por aí (INFORMAÇÃO VERBAL) $)^{2}$

Sendo assim a imagem que os japoneses possuíam do Brasil era a de um local cheio de possibilidades para um recomeço, principalmente os que exerciam atividades agrícolas e não possuíam uma perspectiva dentro do seu próprio país devastado pelos confrontos da guerra e sobre fortes sanções econômicas, restando para alguns destes indivíduos a imigração como única alternativa.

No mesmo período o governo baiano buscava alternativas para o desenvolvimento das atividades agrícolas em algumas áreas consideradas prioritárias, nas quais foram implantados os núcleos coloniais. A implantação do núcleo colonial de Una teve o custo de CR\$ 3.000.000.00, o equivalente a 1.200 salários mínimos da época. Santana (2000, p. 28) acrescenta, "Os imigrantes adquiriam terras para pagamento a médio e longo prazos. A unidade foi dividida em 157 lotes rurais e 6.000 urbanos, que constituía casas simples com instalação rústica, existentes na região". Sobre o contrato para a vinda dos imigrantes explica que:

O contrato firmado entre Brasil e Japão, exigia a permanência mínima de três anos no país, capacidade para trabalhar de pelo menos, três membros da família, recurso individual de 5.000 iens, de cinco anos de experiência anterior em agricultura (SANTANA, 2000, p. 26).

\footnotetext{
${ }^{2}$ Tsuyoshi Izosaki, agricultor. Entrevista gravada na colônia japonesa-Una, 16-12-98-CEDOC-UESC.
} 
Neste período as passagens para a vinda dos imigrantes eram financiadas pelo governo japonês, no entanto as exigências contratuais demonstram as intenções do governo brasileiro com a vinda deste contingente imigratório, que era basicamente de explorar a força de trabalho vista como mais tecnificada e que os imigrantes cumprissem a qualquer custo o papel de agente de desenvolvimento que lhes foi imputado, tendo como obrigação básica trabalhar para que fossem agentes modernizadores da agricultura local. As colônias ficavam sob o controle da Campanha de Revenda e Colonização (CRC), que era o órgão responsável pela seleção das famílias nipônicas, para isso eram realizados exames de saúde e aptidão a atividades agrícolas. Esses imigrantes recebiam assistência médica-dentária, social, técnica e financeira. Também era de responsabilidade da CRC o aval para a concessão dos lotes que era feito por financiamento bancário de 10 anos, e ao fim deste período os nipônicos recebiam a escritura das terras que lhes permitiam a aquisição de empréstimos bancários (SANTANA, 2000).

Para fazer a aquisição de lotes a Campanha de Revenda e Colonização, instituía algumas regras aos japoneses, dentre elas: residir no lote; obedecer às diretrizes da administração; cultivar mais da metade do lote, no mínimo; pagar os compromissos; revelar aptidão para a vida em comunidade; participar de reuniões; ter capacidade para variar o sistema rotineiro do trabalho no campo. Um outro fator que demostra o caráter deste episódio migratório se dá pelo fato que ao chegarem nos núcleos coloniais as famílias nipônicas recebiam uma casa, na qual se verificava uma placa onde constava o nome do líder da família. Além disso, recebiam instrumentos para o trabalho agrícola, escola e auxílio financeiro para os filhos (SANTANA, 2000).

O primeiro grupo de imigrantes japoneses destinados a Bahia chegou ao Rio de Janeiro em agosto de 1953, a bordo do navio Amerika Maru. Em virtude da distância geográfica e das condições do navio em que eram transportados, e o tempo de duração da viagem, o processo de migração se tornava ainda mais penoso, havendo inclusive durante a viagem ocorrências de doenças e até mesmo casos de morte. Esses momentos difíceis são registrados no seguinte relato do imigrante Masafumi Tateishi:

A viajem do Japão para o Brasil durou 45 (quarenta e cinco) dias. O navio Amerika Maru saiu do porto de Kobe (Kobe é aquela cidade que houve um terremoto muito grande), em direção a Los Angeles. Los Angeles é o primeiro porto que a gente encosta nos Estados Unidos. Ver nada, só água. O navio trazia umas trezentas famílias. O ruim da viagem era a doença. Essa doença contagiosa, como sarampo e conjuntivite. Eu mesmo contraí sarampo no navio. Fiquei num compartimento destinado a doentes, um hospitalzinho. Fiquei quinze dias internado. Nós viajamos na terceira classe. Era um local

Geopauta, Vitória da Conquista, ISSN: 2594-5033, V. 4, n.3, 2020, p.(116-131) http://periodicos2.uesb.br/index.php/geo, 
abafado escuro. Lembro-me que na viagem, faleceu uma criança de 4 (quatro) anos. Ela foi sepultada no oceano[...] (INFORMAÇÃO VERBAL). ${ }^{3}$

Depois do trajeto entre o Japão e o Brasil a bordo do navio Amerika Maru e em função dos núcleos coloniais ainda estarem em fase de estruturação os japoneses foram dirigidos à hospedaria de imigrantes da Ilha das Flores, em território fluminense onde permaneceram por dois meses, posteriormente foram embarcados até o porto de Ilhéus no navio Brasileiro Poconé (MARTINS,1988; JESUS,2015). De Ilhéus, seguiram de caminhão rumo ao núcleo colonial de Una, ao todo foram 38 famílias, 235 pessoas, com as passagens foram financiadas pelo governo japonês, no entanto, em abril de 1966 a cobrança da dívida foi cancelada, tendo em vista o favorecimento do grande número de imigrante que ainda não tinham saudado a dívida.

Vencida a viagem, se iniciaram outros desafios, os que são comuns a qualquer grupo de imigrantes, o de adaptação e fixação no novo território a eles destinados, para os japoneses este se constituíram em um dos maiores desafios, haja vista o distanciamento e diferenciações culturais entre nipônicos e brasileiros. O idioma, a precariedade da estrutura, a cultura, a culinária, a religião, obstáculos que estiveram presentes desde os primeiros momentos em no brasileiro e perduraram por algum tempo

Nas colônias enfrentaram obstáculos no processo de ambientação, conforme relembram o imigrante Masafumi Tateishi em outro trecho da entrevista:

[...] A vida no Brasil era muito difícil, um choque e tanto. Para dizer melhor, na casa que eu nasci, no Japão, já havia água e gás encanado. Para quem tinha gás encanado passar a queimar lenha, é grande diferença. A comida foi uma dificuldade para nós aceitar (feijão e jabá). Teve alguns que morreram de fome, outros ficaram muito doentes com as picadas de insetos e cobras. Outro problema era desmatar lote. Às vezes meu pai chegava em casa com as mãos ensanguentadas, dos espinhos e dos instrumentos que usava para cortar as árvores. Então, a gente deu muito duro, viu? Eu mesmo era pequeno, mas enquanto não estudava, era na roça direto, trabalhando duro na lavoura, pois o solo precisava de muitos cuidados (INFORMAÇÃO VERBAL).

Houve muitos choques culturais entre os japoneses recém-chegados e os habitantes locais, pois a alimentação da população nas proximidades do núcleo colonial na época era

\footnotetext{
${ }^{3}$ MASAFUMI, Tateishi,58 anos. Entrevista gravada em Una, 25-09-99-CEDOC-UESC, Cedida gentilmente para esta pesquisa

${ }^{4}$ Idem

Geopauta, Vitória da Conquista, ISSN: 2594-5033, V. 4, n.3, 2020, p.(116-131) http://periodicos2.uesb.br/index.php/geo, Este é um artigo de acesso aberto sob a licença Creative Commons da CC BY, editado nas Normas ABNT-2018
} 
basicamente constituída por farinha de mandioca e feijão, no entanto os hábitos alimentares foi só um dentre os vários estranhamentos, que com o passar dos anos foram amenizados, haja visto que a convivência entre nipônicos e brasileiros foi bastante complexa, ao ponto de os brasileiros que possuíam propriedades nos arredores da colônia evitarem o contato com os imigrantes (SANTANA, 2000). Além destas questões de viés cultural, o solo anunciado como fértil, necessitava constantemente de adubação o que era custoso e submetia os imigrantes a constantes viagens até a cidade em estradas em péssimo estado de conservação para adquirir fertilizantes como podemos conferir na seguinte narrativa sobre a infraestrutura do núcleo colonial de Ituberá:

Os primeiros que por lá chegaram depararam-se com uma área rural, aonde se chegava através de estradas vicinais impossíveis de serem cruzadas em períodos de chuva. A área praticamente inabitada conduzia a certo isolamento, que somado às diferenças de visão de mundo, de modo de ser e de comportar-se, dificultaria a adaptação (JESUS, 2015, p.100).

Outro fator surpresa para as atividades agrícolas dos colonos foi à instabilidade climática na região, o que não lhes permitiam um maior planejamento das atividades agrícolas. Para além destas dificuldades de estrutura, climáticas e socioculturais enfrentadas pelos nipônicos, houve ocorrências de epidemias como o da malária, que gerou uma grande revolta no grupo colonos nipônicos como relata Goisho Nishimota em seu depoimento:

Eles ficaram revoltados com as condições a que foram submetidos e frustrados, por não haver no local, a quantidade de mata virgem e madeira grossa explorada, exigiram o aumento de ajuda de custo, mudança de região, o dobro de quantidade de terras concedidas anteriormente e garantias contra as pragas e danos à produção. As autoridades diziam que as exigências eram injustificáveis, argumentando que engenheiros agrônomos japoneses e brasileiros verificaram previamente as condições territoriais de Una, que os imigrantes trouxeram dinheiro próprio, e que inicialmente, a ajuda de custos era suficiente para o sustento, até o termino do prazo calculado para produção (INFORMAÇÃO VERBAL) ${ }^{5}$

Diante dos acontecimentos não previstos, houve intervenção da Policia Federal do Brasil, o que gerou repercussão no Brasil e no Japão. Algumas das reivindicações foram atendidas, como o aumento da ajuda de custo e por consequência, alguns colonos foram

\footnotetext{
${ }^{5}$ GOISHO NISHIMOTA, 82 anos. Entrevista gravada em sua residência. Núcleo colonial de Una, em 23-10-99-CEDOCUESC
}

Geopauta, Vitória da Conquista, ISSN: 2594-5033, V. 4, n.3, 2020, p.(116-131) http://periodicos2.uesb.br/index.php/geo, 
transferidos do núcleo de Una para o de Ituberá, entanto a evasão dos nipônicos das estruturas propostas pelos núcleos coloniais era bastante substancial de maneira que na década de 1970 eram contabilizados apenas 185 indivíduos nipônicos em toda a mesorregião sul da Bahia (Tabela 1).

Tabela 1- distribuição dos imigrantes japoneses na mesorregião Sul da Bahia - 1970

\begin{tabular}{c|c}
\hline MICRORREGIÃO & IMIGRANTES JAPONESES \\
\hline Cacaueira & 98 \\
Tabuleiros de Valença & 27 \\
Litorânea extremo Sul & 63 \\
Interiorana extremo Sul & 03 \\
\hline Total & 185 \\
\hline
\end{tabular}

Fonte: Censo Demográfico, IBGE, 1970.

Os imigrantes que seguiram residindo nos núcleos coloniais dedicaram-se inicialmente à horticultura. $\mathrm{O}$ entendimento foi de que os recém-chegados ainda não possuíam experiência na lida com a roça, portanto, o cultivo de hortaliças era menos trabalhoso e com um retorno em curto prazo. Inicialmente o cultivo era para subsistência e depois passou para abastecimento do mercado externo, com o avançar do tempo e os novos conhecimentos, à medida que foram se adaptando a à vida na colônia, começaram a implantar cultivos perenes e de maior valor agregado como: cravo-da-índia, pimenta do reino, seringueira, dentre outras culturas agrícolas que garantiram o sustento e a prosperidade das famílias nipônicas assentadas de maneira singular no espaço agrário regional, como podemos observar no seguinte relato de Jesus (2015, p.107) "Das hortaliças ao cravo-da-índia, da pimenta-doreino ao cupuaçu, do rambotã ao mangustão, também há registros da aventura em lavouras como o dendê e a seringueira, já praticadas na região, antes de sua chegada na região". O espírito inovador e a dedicação exitosa dos japoneses do núcleo colonial de Ituberá também foram descrita numa matéria do IBGE enriquecida pelos relatos de Yuriana Kuratani, uma descendente deste grupo de migrantes que apresenta a seguinte narrativa:

Padeiro de profissão, o avô de Yuriana serviu à marinha japonesa durante a Segunda Guerra. Já aqui no Brasil, seu primeiro negócio foi o cultivo de dendê, que deu prejuízos. "Foi quando meu avô começou a produzir pimenta 
do reino que tudo começou a melhorar. Ele foi comprando mais pedaços de terra e ampliando a produção" (INFORMAÇÃO VERBAL) ${ }^{6}$.

Apesar dos desafios e contradições encontrados ao longo de todo o processo, relatos como este tornam nítido que para alguns imigrantes a vinda ao Brasil foi exitosa e ainda podemos nos deparar com bons frutos desta experiência no espaço agrário regional, contribuindo para o desenvolvimento da agricultura local, como podemos conferir no relato de Yuriana no seguinte trecho da reportagem:

Meu pai faleceu em 2015 e deixou três hectares e meio de terra para cada um dos filhos. Cuido da minha área e das áreas de dois irmãos, que não vivem na zona rural. Produzo banana, mamão, maracujá, cravo, mas o nosso principal negócio é o cacau. O cacau é uma maravilha para gente! Quero investir mais no cacau, porque é dinheiro entrando o ano todo", comemora. (INFORMAÇÃO VERBAL) ${ }^{7}$.

Este relato trás o desfecho deste processo, mostrando que após algumas décadas a presença nipônica ainda é notória e promete perdurar no espaço agrário da região sul da Bahia.

\section{Considerações finais}

A maioria das pesquisas com relação a imigração japonesa no Brasil se concentra no período pré segunda guerra mundial, fase esta que está compreendida a partir de 1908, quando chegou o navio Kasato Maru que tinha como destino o estado de São Paulo e outros estados da região sul do Brasil, em que serviam de mão de obra para a lavoura cafeeira. Este ciclo de imigração teve fim com a segunda guerra mundial (1939-1945), na qual Brasil e Japão ocuparam lados opostos e romperam as relações diplomáticas. No entanto, com o fim da guerra e o reestabelecimento das relações diplomáticas entre os dois países, depois de um longo processo de negociações, deu-se início ao segundo ciclo da imigração nipônica, iniciada nos anos 50, tendo em vista que este fluxo migratório era de grande interesse tanto do Japão devido a sua reestruturação no pós-guerra, quanto para Brasil com sua histórica demanda por mão de obra rural e intenções de modernização do campo e ocupação dos vazios demográficos, missões estas para as quais o imigrante japonês era considerado o ideal.

\footnotetext{
${ }^{6}$ Extraido de Agência IBGE notícias, 27 de dezembro de 2019

${ }^{7}$ Extraido de: Agência IBGE notícias, 27 de dezembro de 2019

Geopauta, Vitória da Conquista, ISSN: 2594-5033, V. 4, n.3, 2020, p.(116-131) http://periodicos2.uesb.br/index.php/geo, Este é um artigo de acesso aberto sob a licença Creative Commons da CC BY, editado nas Normas ABNT-2018
} 
Do processo de viagem até a adaptação à nova realidade no espaço agrário sul baiano uma série de desafios lhes foram imputados, perpassando por precariedade de estrutura que lhes eram oferecidas, níveis de desenvolvimento diferenciados entre a realidade japonesa e a brasileira, bem como questões climáticas. Apesar dos obstáculos enfrentados pela população nipônica, nos núcleos coloniais nos quais eles residiam, pode-se afirmar que foi, na sua maior parte bem-sucedida. As intenções do governo brasileiro foram alcançadas, como a diversificação de culturas agrícolas, pois se atribui aos nipo-brasileiros a inserção e sucesso de culturas pioneiras de alto valor agregado, que hoje constituem a economia agrária local da região Sul da Bahia.

\section{Referências}

BAENINGER, R. Contribuição da Academia para o Pacto Global da Migração: o olhar do Sul. In: Basinger, R. et al. (Org.). Migrações Sul-Sul. 1ed.Campinas:

NEPO/UNICAMP/UNFPA, 2018, v. 1, p. 17-22.

BECKER, O. M. Mobilidade espacial da população: conceitos, tipologia, contextos. In: CASTRO, I. E; GOMES, P. C. C.; CORRÊA, R. L. (Org.). Explorações Geográficas. Rio de Janeiro: Bertrand Brasil, 1997, v, p. 319-367.

BRASIL, A. E. Organização sócio-espacial e transformações socioeconômicas do núcleo JK, Mata de São João/ Camaçari (BA). Dissertação (Mestrado em Geografia) Universidade Federal da Bahia. 2004. 183p.

BRASIL. Decreto-Lei no 30.390, de 14 de janeiro de 1952. Disponível em: <https://www2.camara.leg.br/legin/fed/decret/1950-1959/decreto-30390-14-janeiro-1952339889-publicacaooriginal-1-pe.html>. Acesso em 10/03/2020.

BRASIL Decreto-Lei no 34.293, de 20 de outubro de 1953. Disponível em: <https://www2.camara.leg.br/legin/fed/decret/1950-1959/decreto-34293-20-outubro1953325670-publicacaooriginal-1-pe.html>. Acesso em 10/03/2020.

BRASIL Decreto-Lei no 7.967, de 18 de setembro de 1945 Disponível em:< https://www2.camara.leg.br/legin/fed/declei/1940-1949/decreto-lei-7967-18-setembro-1945416614-norma-pe.html>. Acesso em 15/02/2020.

GOISHO NISHIMOTA, 82 anos. Entrevista gravada em sua residência. Núcleo colonial de Una, em 23-10-99-CEDOC-UESC

INSTITUTO BRASILEIRO DE GEOGRAFIA E ESTATÍSTICA-IBGE. Na Bahia, filhos de japoneses investem no cacau. Agência IBGE notícias. 27 de dezembro de 2019. Séries Especiais. Disponível em: < https://agenciadenoticias.ibge.gov.br/agencia-noticias/2012agencia-de-noticias/noticias/26478-na-bahia-filhos-de-japoneses-investem-no-cacau>. Acesso em: 01/04/2020.

Geopauta, Vitória da Conquista, ISSN: 2594-5033, V. 4, n.3, 2020, p.(116-131) http://periodicos2.uesb.br/index.php/geo, Este é um artigo de acesso aberto sob a licença Creative Commons da CC BY, editado nas Normas ABNT-2018 
JESUS, E. S. Os nipo-baianos de Ituberá: trajetórias, memórias e identidades de imigrantes no Baixo-Sul da Bahia (1953-1980). Tese (Doutorado em Cultura e Sociedade)Universidade Federal da Bahia,2015. 212p.

LEÃO NETO, V. C. A crise da imigração japonesa no Brasil (1930 -1934): contornos diplomáticos. Brasília: Fundação Alexandre de Gusmão, 1989 (Série Relações Internacionais). 358p.

LYRA, H. J. B. Colonos e Colônias: uma avaliação das experiências de colonização agrícola na segunda metade do século XIX. Dissertação (Mestrado em Ciências Sociais) Universidade Federal da Bahia. 1982. 197p.

MARTINE, G. A globalização inacabada: migrações internacionais e pobreza no século 21. São Paulo em Perspectiva, v. 19, p. 3-22, 2005. Disponível em: <http://www.scielo.br/scielo.php?script=sci_arttext\&pid=S0102-88392005000300001>. Acesso em 01/04/2020.

MARTINS, R. G. Japão do pós-guerra: a contribuição do Brasil. Cruz das Almas: Mansão Sol Nascente, 1988. p. 32.

MASAFUMI, Tateishi,58 anos. Entrevista gravada em Una, 25-09-99-CEDOC-UESC MENEZES, A. M. Utopia, imigração e a Colônia alemã de Una, Bahia no contexto histórico. Textos de História (UnB), v. 16, p. 35-78, 2008.

OLIVEIRA, L. L. O Brasil dos imigrantes. 2. ed. Rio de Janeiro: Jorge Zahar, 2002. 72p PETRONE, M. T. S, O imigrante e a pequena propriedade: 1824-1930. São Paulo. Brasiliense, $1982.89 \mathrm{p}$.

RANGEL, C.M. Geografia da população. Ilhéus: Universidade Estadual de Santa Cruz, 2018.Notas de aula.

SANTANA, A.R.S. A presença japonesa na história de Una. Monografia (Graduação em História) - Universidade Estadual de Santa Cruz, 2000. 46f.

SILVA, L. M. A imigração japonesa como fator de influência para o desenvolvimento da agricultura familiar: Estudo de caso da zona rural de Brazilândia - DF. Monografia (Graduação em Licenciatura e Bacharelado) - Universidade de Brasília, 2013. 123f.

TSUYOSHI IZOSAKI, agricultor. Entrevista gravada na colônia japonesa-Una, 16-12-98CEDOC-UESC.

UEHARA, Alexandre R. Presença Nikkei no Brasil: integração e assimilação. In: DEPARTAMENTO DE LETRAS ORIENTAIS. Estudos Japoneses. São Paulo: Faculdade de Filosofia e Letras, n.28, 2008. 